3 Research Square
Preprints are preliminary reports that have not undergone peer review.

They should not be considered conclusive, used to inform clinical practice, or referenced by the media as validated information.

\title{
Noise-induced Hearing Loss and Hypertension Among Occupational Noise-exposed Workers: a Pilot Study Based on Baseline Data
}

\author{
Long Miao \\ Southeast University \\ Juan Zhang \\ Southeast University \\ Lihong Yin \\ Southeast University \\ Yuepu Pu ( $\square$ yppu@seu.edu.cn ) \\ Southeast University
}

\section{Research Article}

Keywords: Occupational noise, Noise-induced hearing loss, Hypertension, Prevalence, Risk

Posted Date: October 27th, 2021

DOI: https://doi.org/10.21203/rs.3.rs-1014638/v1

License: (a) (i) This work is licensed under a Creative Commons Attribution 4.0 International License. Read Full License 


\section{Abstract}

Background: Noise is a widespread occupational hazardous factor affecting the health of workers in occupational health field. Noise-induced hearing loss (NIHL) and hypertension are the important biological adverse effects caused by occupational noise exposure. This study aimed to determine the binaural high frequency $(3,4$, and $6 \mathrm{kHz})$ threshold on average (BHFTA) and levels of systolic blood pressure (SBP) and diastolic blood pressure (DBP), to assess the prevalence of NIHL and hypertension and determine the factors influencing the risk of both, and to evaluate the association between NIHL and hypertension among occupational noise-exposed workers.

Methods: Questionnaire and occupational health checkup were performed to collect the personal information and physical examination data. Finally, baseline data from 42,588 occupational noise-exposed workers were analyzed. Noise intensity in the workplaces was measured using sound level meter. Pure tone audiometry (PTA) was measured at 3, 4 and $6 \mathrm{kHz}$ using diagnostic audiometer. Moreover, blood pressure level was measured using automated sphygmomanometer.

Results: The mean levels of BHFTA, SBP, and DBP were $23.09 \pm 11.32 \mathrm{~dB}, 126.85 \pm 15.94 \mathrm{~mm} \mathrm{Hg}, 79.94 \pm 11.61$ $\mathrm{mm} \mathrm{Hg}$. Of the 42,588 subjects, the prevalence of $\mathrm{NIHL}$ and hypertension were $24.38 \%(n=10,383)$ and $25.40 \%$ $(n=10,816)$. The results suggested that higher risk of $\mathrm{NIHL}$ and hypertension were more likely to be the subgroups of male gender, aged $>35$ years, noise exposure time $>5$ years, noise exposure level $>85 \mathrm{~dB}(\mathrm{~A})$ and smoking. The BHFTA, SBP, and DBP levels increased with the age, noise exposure time and exposure level $\left(P_{\text {trend }}\right.$ $<0.001)$. Besides, similar trends were also observed in the prevalence of $\mathrm{NIHL}$ and hypertension. Furthermore, there was a significant association of $\mathrm{NIHL}$ with hypertension. We found that $32.25 \%(n=3,348)$ workers with $\mathrm{NIHL}$ had hypertension. The mean levels of SBP and DBP in NIHL workers were significantly higher than those with normal hearing $(P<0.001)$. Besides, workers with $\mathrm{NIHL}$ had a significantly higher risk of developing hypertension than normal hearing workers (adjusted $\mathrm{OR}=1.07,95 \% \mathrm{Cl}=1.02-1.13$ ).

Conclusion: Our current findings suggest that the prevalence of $\mathrm{NIHL}$ and hypertension are high in the studied workers and occupational noise exposure is an important factor. Therefore, it is urgent to reduce noise exposure in the workplaces and to strengthen industrial noise monitoring.

\section{Background}

In general, noise is known as a kind of sounds, which can be irritating or loud enough to endanger everyone. There are various types of noise, such as traffic noise, construction noise, and workplace noise. Nowadays, noise pollution has become an important public health problem. It's worth noting that noise is a widespread occupational hazard factor severely affecting workers' health in the field of occupational health. Available evidence suggested that prolonged noise exposure could lead to multiple harmful effects, including annoyance [1], sleep disturbance [2], learning impairment [3, 4].

To our knowledge, the most direct and severe impact of noise is the damage to the auditory system, and the most serious adverse effect is the occurrence of noise-induced hearing loss (NIHL). NIHL is a progressive sensorineural hearing loss characterized by noise-induced auditory threshold shift at high-frequency. NIHL is a major occupational-related disease and is a severe occupational health problem in the workplace safety [5]. It is 
worth noting that about ten percent of the world's population permanently are expose to high-intensity noise environment and are at risk of developing $\mathrm{NIHL}$ [6]. About $16 \%$ of worldwide hearing loss in adults was found to be caused by occupational noise [7]. A recent study showed that occupational noise exposure caused 7 to $21 \%$ hearing loss in workers, with the lowest incidence in industrialized countries and the highest in developing countries [8]. It was estimated that about 22 million workers were exposed to hazardous occupational noise in the USA [9]. Besides, approximately $\$ 242$ million was cost annually on compensation due to occupational $\mathrm{NIHL}$ [6]. In Europe, approximately $54 \%$ of population were exposed to road traffic noise level high than $55 \mathrm{~dB}$ each year that could affect health [10]. With the rapid development of industry in China, noise is widespread in various industrial places, and a larger number of workers exposed to noise. Nowadays, NIHL has been the third largest occupational health hazard in China, the incidence of which has been increasing [11]. Zhou $\mathrm{J}$ et al. [12] has conducted a meta-analysis and found that the prevalence of occupational NIHL was $21.3 \%$ in China.

$\mathrm{NIHL}$ could cause communication disorder and social isolation, thus leading to self-abasement, cognitive decline, and depression [13]. Therefore, it is an extreme important public health goal to prevent NIHL and reduce its adverse effects.

Except for adverse effects on auditory function, noise, as a psychosocial stressor, could induce biological effect on cardiovascular system and lead to hypertension $[14,15]$. Previous studies suggested that the mechanism by which noise causes hypertension may be through activation of the hypothalamus-pituitary-adrenal gland and sympathetic nervous system, thus resulting in elevated levels of norepinephrine, epinephrine, and cortisol [6]. Some studies have documented that workers exposed to occupational noise had a distinctly elevated blood pressure $[16,17]$ or had a higher risk of hypertension $[18,19]$. It has reported that $9.4 \%$ of cardiovascular disease deaths are caused by hypertension [20]. Skogstad $\mathrm{M}$ et al. [21] found that occupational noise exposure can increase hypertension risk with a hazard ratio (HR) of $1.38(95 \% \mathrm{Cl}=1.01-1.87)$. A cross-sectional study enrolling 1,390 occupational noise-exposed workers and 1,399 non-noise-exposed workers observed that the prevalence of hypertension was $17.8 \%$ in noise-exposed workers, and the SBP and DBP levels were significantly higher than those in the non-noise-exposed workers [22]. Similarly, Chang et al. [23] confirmed that long-term noise exposure could cause the elevated blood pressure levels and higher risk of hypertension. In addition, a study of 1,729 workers performed by de Souza TC et al. [24] also proved that noise exposure was associated with hypertension. Nowadays, hypertension has become one of the top three hazards of the global burden of disease, accounting for $7.0 \%$ of the global disability-adjusted life-years (DALYs) [20]. Thus, it is necessary to take early intervention for prevention of noise-induced hypertension and its adverse effects.

Occupational noise as a prevalent occupational health risk may be present in many workplaces affecting workers' health and putting the workers' health at a high risk. In addition, considering the harmful effects of occupational noise on human health, we conducted this study to investigate the status of NIHL and hypertension, determine the potential risk factors, and evaluate the association between NIHL and hypertension by analyzing the baseline data from occupational health checkups of occupational noise-exposed workers.

\section{Materials And Methods}

\section{Study subjects}

In this cross-sectional study, a total of 44,305 workers exposed to occupational noise who accepted occupational health checkups between 2015 and 2017. To avoid potential biases, a total of 1,717 workers who 
gave incomplete information of occupational noise exposure, did not accomplish the occupational health examinations, had a family history of deafness and diagnosed hearing loss, otitis media, skull trauma, nervous tinnitus could impair normal hearing, had a history of cardiovascular diseases and hypertension, medical diagnosis history of hypertension, and previous or current use of drugs that could cause hearing loss and hypertension were excluded from this study. Finally, 42,588 workers meeting the above inclusion criteria were recruited in this study. All included study participants were the frontline workers exposed to occupational noise under different operating post such as polishing, cold rolling, electrical welding, grinding, riveting, stamping, etc.

This study was reviewed and approved by the Ethics Committee of Zhongda Hospital, Affiliated Hospital of Southeast University (approval No: 2020ZDSYLL150-P01) before this current study commenced. Informed consents were also obtained from each participant.

\section{Questionnaire survey}

A structured questionnaire was performed to collect information on demographic characteristics of all workers before occupational health checkups. The information included age, noise exposure time, hereditary history of deafness and hypertension, family history of cardiovascular diseases, smoking and drinking status, history of ear-related diseases (ear infections, head injury/trauma, and tinnitus), previous medical diagnosis of hypertension, and previous or current use of drugs was gathered. The information was used to screen participants for the current study. The Details of the definitions of smoking and drinking have been proposed elsewhere [25]. In brief, workers had one cigarette per day for the at least one year were defined as smokers. Drinkers were defined as workers consumed a bottle of beer or fifty grams of wine per day for at least one year.

\section{Environmental noise exposure determination}

Noise intensity was measured using sound level meter (TES, Taiwan) and determined according to equivalent continuous $\mathrm{dB}(\mathrm{A})$-weighted sound pressure levels LAeq, 8 h. Cumulative noise exposure (CNE) was calculated and was regarded as the level of individual noise exposure according to LAeq. Therefore, we defined occupational noise exposure as equivalent continuous $\mathrm{dB}(\mathrm{A})$-weighted sound pressure levels of more than 85 $\mathrm{dB}(\mathrm{A})$ during a nominal $8 \mathrm{~h}$ working day.

\section{Pure-tone audiometric examination and NIHL definition}

Occupational noise exposure was defined as a noise exposure level of at least $85 \mathrm{~dB}(\mathrm{~A})$ on a nominal $8 \mathrm{~h}$ workday in this study. Pure-tone audiometric (PTA) examination was subsequently performed by professional audiologist with a pure tone audiometer (Madsen Voyager 522, Taastrup, Denmark). All recruited workers underwent a PTA test after being away from the occupational noise exposure environment for at least fourteen hours or longer. According to the diagnostic criteria (GBZ 49-2014), hearing thresholds of left and right ears were assessed with the method of ascending pure tones at the frequencies of $0.5,1,2,3,4$, and $6 \mathrm{kHz}$. Furthermore, all hearing examinations were conducted in a soundproof room to ensure that the obtained results reflect the true levels of hearing thresholds of workers. In the present study, workers whose binaural high frequency $(3,4$, and $6 \mathrm{kHz}$ ) threshold on average (BHFTA) greater than $25 \mathrm{~dB}$ were defined as NIHL, while those less than $25 \mathrm{~dB}$ were defined as normal hearing. To better describe the status of hearing loss, based on BHFTA, the severity of $\mathrm{NIHL}$ was categorized into five subgroups, including normal hearing ( $\leq 25 \mathrm{~dB}$ ), mild (26-40 dB), moderate (41-70 $d B)$, severe (71-90 dB) and profound ( $\geq 91 \mathrm{~dB})$, respectively [26]. 


\section{Blood pressure measurement and hypertension}

Before blood collection and blood pressure measurement, all workers were asked to fast overnight. Blood pressure was evaluated by an experienced physician using an automated sphygmomanometer (TM-2655P, A\&D Corp., Japan) after workers sat for more than 10 minutes rest. The average value of three repeated blood pressure measurements with 30 seconds interval was applied to reflect the true level of an individual's blood pressure. Workers who had mean resting systolic blood pressure (SBP) $\geq 140 \mathrm{~mm} \mathrm{Hg}$ and/or mean resting diastolic blood pressure (DBP) $\geq 90 \mathrm{~mm}$ Hg were defined as hypertensive.

\section{Statistical analysis}

Descriptive statistics were computed as mean, standard deviation (SD) and frequency percentages. Shapiro-Wilk test was used to determine the normality of continuous variables including SBP, DBP, and binaural high frequency threshold on average. Student's $t$ test and Kruskal-Wallis test were applied to determine the significance differences of continuous variables. Two-side $\chi^{2}$ test was applied to examine statistical differences in frequency distribution of category variables. For the significantly different group, the Mann-Whitney test and $\chi^{2}$ test were used to compare the statistical significance of variables among groups. In addition, multivariate logistic regression, calculated odds ratios (ORs) and 95\% confidence intervals (Cls) to determine the strength of association between selected variables and $\mathrm{NIHL}$ and hypertension by controlling potential confounding factors, such as age, gender, noise exposure time, smoking and drinking status. The SPSS version 23.0 (SPSS, Chicago, Illinois, USA) was performed for all statistical analyses. The statistical significance was set as $P$ values $<0.05$.

\section{Results}

\section{Characteristics of study subjects}

Table 1 summarizes the demographic characteristics of this cross-sectional study comprised 42,588 subjects who exposed to occupational noise. Among the recruited subjects, $74.76 \%$ were male ( $n=31,838$ ), and $25.24 \%$ were female $(n=10,750)$. The mean age was $36.58 \pm 9.56$ years, with $44.30 \%$ of workers were at the age of 18 34 years, $31.38 \%$ were $35-44$ years, and $24.33 \%$ were older than 45 years. The average noise exposure time was $9.20 \pm 8.38$ years, with $38.57 \%$ of workers were exposed to noise for less than 5 years, $30.03 \%$ were in the range of 5-10 years, and $31.40 \%$ had a noise exposure history of greater than 10 years. The average noise exposure level was $88.07 \pm 7.39 \mathrm{~dB}(\mathrm{~A})$, with $37.59 \%$ of workers were exposed to noise level for less than $85 \mathrm{~dB}(A)$, $19.92 \%$ were in the range of $86-91 \mathrm{~dB}(\mathrm{~A})$, and $42.49 \%$ workers had a noise exposure level of greater than $\geq 92$ $\mathrm{dB}(\mathrm{A})$. Furthermore, in all subjects, $33.44 \%$ and $33.52 \%$ were smokers and drinkers, respectively. The binaural high frequency threshold on average of study workers was $23.09 \pm 11.32 \mathrm{~dB}(\mathrm{~A})$.

\section{Prevalence of NIHL and hypertension}

The prevalence of NIHL with different severity are displayed in Table 2. Among the 42,588 subjects, 10,383 workers were diagnosed as having NIHL, with the prevalence of $24.38 \%$. As for the severity of NIHL, the highest number of hearing loss was found on mild (16.76\%). Besides, the prevalence of NIHL by severity was $7.1 \%$ for moderate, declining to $0.45 \%$ and $0.07 \%$ for severe and profound, respectively. As shown in Table 3, the mean levels of SBP and DBP of all workers were $126.85 \pm 15.94 \mathrm{~mm} \mathrm{Hg}$ and $79.94 \pm 11.61 \mathrm{~mm} \mathrm{Hg}$, respectively. Meanwhile, 10,816 workers (25.40\%) were diagnosed with hypertension. 


\section{Stratified analysis of binaural high frequency threshold on average and prevalence of NIHL}

As shown in Table 4, we found that workers in the subgroups of male gender, smoking and drinking had a significantly higher BHFTA compared with female, non-smoking and non-drinking workers $(P<0.001)$. Totally, 8,162 males, 4,289 smokers and 3,715 drinkers out of all the recruited subjects were diagnosed as having NIHL, with the prevalence of $25.64 \%, 30.12 \%$ and $26.02 \%$, significantly higher than the female $(20.66 \%)$, non-smoking (21.50\%) and non-drinking (23.55\%) workers. Male and smoking workers had a significantly higher risk of NIHL (adjusted $\mathrm{OR}=1.51,95 \% \mathrm{Cl}=1.41-1.61 ;$ adjusted $\mathrm{OR}=1.10,95 \% \mathrm{Cl}=1.04-1.16)$. Besides, there was a significant difference in the level of BHFTA between the three subgroups of age, noise exposure time and noise exposure level $(P<0.001)$, and significantly elevated with the cumulative of age, noise exposure time and noise exposure level. Correspondingly, workers aged $35-44(27.44 \%, P<0.001)$ and $>44(39.79 \%, P<0.001)$ with BHFTA of $23.86 \pm 11.45 \mathrm{~dB}$ and $26.47 \pm 14.72 \mathrm{~dB}$ had significantly higher prevalence rates of $\mathrm{NIHL}$ than workers younger than 35 years $(13.75 \%)$. Workers who exposed to noise time $5-10$ years $(30.73 \%, P<0.001)$ and $>10$ years $(35.15 \%, P<0.001)$ with BHFTA of $24.30 \pm 12.06 \mathrm{~dB}$ and $25.16 \pm 13.51 \mathrm{~dB}$ had significantly higher prevalence of $\mathrm{NIHL}$ than noise exposure less than 5 years workers (10.67\%). Moreover, workers exposed to noise level 86-91 dB (A) $(26.56 \%, P<0.001)$ and $\geq 92 \mathrm{~dB}(\mathrm{~A})(26.29 \%, P<0.001)$ with BHFTA of $88.15 \pm 1.91 \mathrm{~dB}$ and $94.97 \pm 2.17 \mathrm{~dB}$ had also higher prevalence of NIHL than noise exposure level less than $85 \mathrm{~dB}(\mathrm{~A})$ workers (21.06\%). Similar results also could be observed in the risk of $\mathrm{NIHL}$, which indicated that the risk of $\mathrm{NIHL}$ in the subgroups of age between 35 and 44 (adjusted $\mathrm{OR}=1.91,95 \% \mathrm{Cl}=1.79-2.04$ ) and $>44$ years $($ adjusted $\mathrm{OR}=3.16,95 \% \mathrm{Cl}=2.96$ 3.37), noise exposure time of $5-10$ years (adjusted $\mathrm{OR}=3.33,95 \% \mathrm{Cl}=3.12-3.54$ ) and $>10$ years (adjusted $\mathrm{OR}=$ $2.73,95 \% \mathrm{Cl}=2.55-2.92$ ), and noise exposure level of $86-91 \mathrm{~dB}(\mathrm{~A})$ (adjusted $\mathrm{OR}=1.36,95 \% \mathrm{Cl}=1.27-1.45$ ) and $\geq 92 \mathrm{~dB}(\mathrm{~A})$ (adjusted $\mathrm{OR}=1.30,95 \% \mathrm{Cl}=1.23-1.37$ ) was significantly higher compared to the aged $<35$ years, noise exposure time $<5$ years and noise exposure level $\leq 85 \mathrm{~dB}(\mathrm{~A})$ groups $(P<0.001)$.

\section{Stratified analysis of the levels of SBP and DBP and prevalence of hypertension}

Table 5 shows the stratified analysis results of SBP and DBP levels and prevalence of hypertension by study groups. There was a significant difference in the levels of SBP and DBP, and the prevalence of hypertension between different gender, age, noise exposure time, noise exposure level, smoking and drinking groups $(P<$ 0.001). The male, smoking and drinking workers had significantly higher levels of SBP and DBP, and prevalence rates of hypertension than the female, non-smoking and non-drinking workers. Besides, we found that a similar result revealing that males and smokers were at significantly higher risk for hypertension (adjusted OR $=2.18$, $95 \% \mathrm{Cl}=2.04-2.34$; adjusted $\mathrm{OR}=1.11,95 \% \mathrm{Cl}=1.05-1.17$, respectively). There was a statistical significance in the SBP and DBP levels among the groups with different age, noise exposure time, and noise exposure level, and both SBP and DBP levels increased with the gradual increase of age, noise exposure time and exposure level $\left(P_{\text {trend }}<0.001\right)$. Besides, the multivariate logistic regression analysis showed that age, noise exposure time and exposure level were associated with the risk of hypertension after adjusting for potential confounders. The subgroups of age 35-44 and $>44$ years had a 2.32-fold and 3.82-fold greater OR for hypertension than age less than 35 years. A similar result in the subgroups of noise exposure time 5-10 and $>10$ years, and noise exposure level 86-91 and $\geq 92 \mathrm{~dB}(\mathrm{~A})$ was also found.

\section{Analysis of association between NIHL and hypertension}


To determine the association between $\mathrm{NIHL}$ and hypertension, all subjects were divided into normal hearing and $\mathrm{NIHL}$ groups. The results showed that the mean levels of SBP $(130.03 \pm 16.89 \mathrm{~mm} \mathrm{Hg})$ and DBP $(82.16 \pm 12.21$ $\mathrm{mm} \mathrm{Hg})$ in 10,383 NIHL workers were significantly higher than those with normal hearing (125.82 $\pm 15.48 \mathrm{~mm}$ $\mathrm{Hg}$ for SBP and $79.23 \pm 11.32 \mathrm{~mm} \mathrm{Hg}$ for DBP $)(P<0.001)$. The prevalence of hypertension in normal hearing group was $23.19 \%$, while $32.25 \%$ in NIHL group, and a statistically significant difference was found between the two groups $(P<0.001)$. Furthermore, compared with normal hearing workers, NIHL workers had 1.07 times higher risk of hypertension after correcting confounding factors (adjusted $\mathrm{OR}=1.07,95 \% \mathrm{Cl}=1.02-1.13)($ Table 6).

\section{Discussion}

Based on the data from occupational health checkups of 42,588 occupational noise-exposed workers, we investigated the levels of SBP, DBP and BHFTA, prevalence of NIHL and hypertension. Besides, we evaluated the association between NIHL and hypertension. Among the included 42,588 subjects, we found that the prevalence of $\mathrm{NIHL}$ and hypertension were $24.38 \%$ and $25.40 \%$. We also found that the prevalence rates of NIHL and hypertension were significantly higher in subgroups of male gender, aged 35-44 and > 44 years, noise exposure time 5-10 and > 10 years, noise exposure level 86-91 and $\geq 92 \mathrm{~dB}(\mathrm{~A})$, and smoking. Higher risks of NIHL and hypertension were also occurred in the above groups. In addition, there was a significant difference between $\mathrm{NIHL}$ and hypertension; the risk of hypertension in NIHL group was 1.07-fold greater than in normal hearing group.

Generally, noise is considered as a set of sounds that could make people irritable or is loud enough to endanger everybody. In environment, there are diverse sources of noise, including transportation noise, occupational noise, and construction noise. Nowadays, noise pollution has been an important and neglected public health issue in the world. Adverse health effects of noise on human beings can be observed on psychologically and physiologically [27]. The WHO reported that mental, behavioral, and neurological diseases affected by noise account for $3 \%$ of global deaths and $10 \%$ of global burden of disease [28]. Recent evidence showed that longterm exposure to environmental noise could cause some adverse health effects, such as sleep disturbance [2], annoyance [28], learning impairment [3], and hypertension [29].

Occupational noise, a common harmful factor that seriously affects health of workers in the field of occupational health. Noise-induced hearing loss (NIHL) is one of the worst adverse health effects induced by occupational noise exposure in workplaces [30]. The WHO reported that about $10 \%$ of the world's population is exposed to high level of noise and at risk of progressing to NIHL [6]. A recent review revealed that occupational noise exposure resulted in $7 \%$ to $21 \%$ of workers' hearing loss, with the lowest incidence in industrialized countries and the highest in developing countries [8]. According to previous study, NIHL is one of the leading occupational related disease in China, accounting for approximately one-sixth of the annual increase of occupational disease [11]. Many epidemiological investigations showed that high frequency hearing loss is mainly caused by occupational noise exposure [31, 32]. In this study, the prevalence of NIHL was $24.38 \%$, which was higher than the results from research performed by Lie A et al. [8] showing that approximately 7 to $21 \%$ of NIHL caused by occupational noise exposure. Therefore, we could conclude that NIHL has become an urgent occupational health problem that damages workers' health in China. In this study, we observed that male workers had a significantly higher risk of NIHL than females. Nelson DI et al. [7] has reported that the harmful effects of occupational noise exposure on NIHL were larger among males than females. Previous studies also 
suggested that males may suffer more effects after occupational noise exposure than females [33]. The gender difference might be due to the differences in auditory sensitivity. Besides, another possible explanation may be physiological differences induced by hormones between sexes. Relevant studies have found that estrogen and its signaling pathways may protect women from hearing loss [33]. It has been shown that a key factor contributing to NIHL is oxidative stress damage to sensory hair cells [34]. In the present study, a significantly higher risk of NIHL was observed in workers aged $>35$ years, noise exposure time $>5$ years, and noise exposure level $>85 \mathrm{~dB}(\mathrm{~A})$, with adjusted ORs gradually increasing with increasing of age, noise exposure time and exposure level, which was consistent with from previous studies [35]. A recent study has reported that age influenced hearing thresholds over time, and age groups of 30-44 years and 45-59 years workers were at higher risk of exposing to occupational noise and had higher hearing thresholds [36]. Prolonged exposure to occupational noise has been shown to damage cochlear hair cells, thus leading to irreversible NIHL. In addition, the prevalence of hearing loss was also reported to increase with the increasing level of noise exposure [37-39]. It should be worth noting that aging and duration with noise were the most common cause of NIHL, and both closely related to the formation of reactive oxygen species, which was the major product of oxidative stress [40].

Smoking was found to be associated with an increased risk for hearing loss [41, 42]. Wang D et al. [43] also found that smoking was an independent risk factor for NIHL, and there was a dose-response relationship between smoking and NIHL risk. In this study, we found that a similar result revealing smoking was significantly associated with the risk of NIHL. However, the specific pathogenic mechanisms underlying smoking increases the risk of hearing loss is not well understood. Available evidence has revealed that smoking may damage cochlea hair cells and cause hearing loss by increasing carboxyhemoglobin or reducing cochlear blood flow to the cochlea [44]. Previous studies found a moderate intake of alcohol had a protective effect on hearing [45], but frequent alcohol consumption could increase the risk of hearing loss [46]. In contrast, a previous study has found that no significant association between drinking and the risk of NIHL [47], which showed the same results as our study. Further studies in more detail are necessary to investigate the mechanism underlying this inconsistent.

It has been reported that persons with chronic and repeated exposure to noise appeared a persistent increased of blood pressure or a higher risk of hypertension $[48,49]$. In this study, altogether, $25.40 \%$ of the workers included in our study had hypertension, suggesting a higher incidence of this disease. Workers particularly in the subgroups of male gender, aged $>35$ years, exposure time with noise $>5$ years, noise exposure level $>85 \mathrm{~dB}(A)$ and smoking were more likely to develop hypertension, the results were in accordance with observed trends in previous studies [13,40,50,51]. Males were observed with much higher blood pressure levels and higher risk of hypertension compared with females. The gender difference might be due to the differences in auditory sensitivity and pathogenesis of cardiovascular diseases. A cross-sectional study observed that a significant dose-response relationship between age, noise exposure time, noise exposure intensity and the risk of hypertension [22, 52]. Similarly, Chang et al. [23] performed a cohort study recruiting 578 workers and found a significant exposure-response between the noise exposure intensity and the risk of hypertension. Smoking has been identified as a risk factor for coronary heart disease, stroke, and hypertension by abundant evidence [5355]. Our findings showed that workers with these characteristics were high risk individuals of developing hypertension in occupational noise exposure settings. According to recent reports showed that the consequence of hypertension induced by noise exposure might be due to stress response, thus resulting in the elevated level of stress hormones such as catecholamine $[56,57]$. A study on the health effects of environmental noise 
exposure on cardiovascular disease found that catecholamine could raise myocardial contractibility and enhance the output of blood pressure and cardiac by regulating $\beta-1$ receptors [58]. Yet other studies have not found any significant correlation [59-61]. There is still a lack of consensus on this issue. It is remarkable that the differences of results observed in different studies may be influenced by population studied and auditory sensitivity. Therefore, further studies in more detail are needed to precisely determine the mechanism underlying this inconsistent.

To explore the association between NIHL and hypertension, we divided the workers into normal hearing group and NIHL group according to the level of BHFTA. The current study suggested that NIHL workers had a significantly higher level of SBP and DBP compared to those in normal hearing group. Similarly, a study ( $\mathrm{n}=$ 618) revealed that the mean levels of SBP and DBP in the NIHL group were significantly higher than those in the normal hearing group [62]. Meanwhile, the findings of our study suggested that the prevalence rate of hypertension in NIHL differed from that in normal hearing workers by $9.1 \%$; the risk of developing hypertension in $\mathrm{NIHL}$ workers was 1.07 times that of normal hearing workers. Kuang D et al. [52] investigated the association of high-frequency hearing loss and hypertension among occupational noise exposed workers and indicated that workers with mild high-frequency hearing loss (hearing level $>25$ but $<40 \mathrm{~dB}$ ) had a higher hypertension risk of $34 \%$. Also, the findings of another research involving 119 workers indicated that high frequency hearing loss was significantly associated with hypertension [63]. In addition, a study enrolling 790 male aircraft-manufacturing individuals reported that workers with high frequency hearing loss ( 4 and $6 \mathrm{kHz}$ ) had higher risk of hypertension [64]. Our current findings were consistent with the above-described findings regarding the association between NIHL and high levels of SBP and DBP, and hypertension risk. Therefore, our study provided evidence that NIHL may be associated with the risk of hypertension, and it may act a potential biomarker of noise-induced hypertension for occupational noise-exposed workers.

\section{Strengths and limitations}

Our present study is a cross-sectional study based on the data from occupational health checkups of 42,588 occupational noise-exposed workers. Strengths of the study are large sample size and high response rate among the subjects, as well as the occupational health checkups performed by certified and experienced physician and

audiologists, thus ensuring the accuracy and credibility of all data; findings obtained based on this large sample size is more convincing. Besides, subgroup analysis of variables was conducted to avoid potential confounding factors. However, several limitations are also present in the current study and need to be mentioned. First, this study was based on a cross-sectional analysis, the results should be verified by prospective cohort studies in the future. Second, the questionnaire survey based on self-report measures of participants, which may cause bias to the results of the study. Third, some important information was not collected, such as hearing protection measure, the usage of headphones, BMI, dietary habit, etc., which were crucial factors influencing hearing loss and hypertension. Hence, in future studies, we will pay more attention to collecting the above missing data to make the results more convincing.

\section{Prevention recommendations on noise health hazards}

It can conclude that the prevalence rates of $\mathrm{NIHL}$ and hypertension are high in our study workers and occupational noise exposure is an important factor. We suggest that reducing noise exposure in the workplaces and improving preventive measure to prevent occupational noise-exposed workers from NIHL, hypertension, and 
other adverse health effects. In addition, occupational noise-exposed workers should strengthen own protection consciousness and wear earplugs properly while working.

Regular PTA examination and blood pressure monitoring should be performed by physicians among occupational noise-exposed workers. Also, safety standards for noise in the workplaces should also be monitored regularly to decide if compliance with the safety standards of industrial noise. Finally, if workers were identified to have potential risk of developing NIHL and hypertension by screening should be transferred to new job post with less or no noise exposure.

\section{Conclusion}

In this study, based on the data of occupational health checkups from 42,588 occupational noise-exposed workers, we can draw the following conclusions: (1) a large number of workers exposed to occupational noise, and the mean noise exposure time was > 9.20 years; (2) the prevalence rates of NIHL and hypertension were $24.38 \%$ and $25.40 \%$, respectively; (3) the prevalence of $\mathrm{NIHL}$ and hypertension increased with age, noise exposure time and exposure level; (4) significantly higher risk of NIHL and hypertension was observed especially in the group of male gender, aged $>35$ years, noise exposure time $>5$ years, noise exposure level $>85 \mathrm{~dB}(A)$, and smoking; (5) finally, of all the study participants, 32.25\% workers with NIHL were diagnosed with hypertension, indicating that workers with $\mathrm{NIHL}$ were at higher risk of developing hypertension than that of normal hearing workers.

The findings of this study suggest that occupational noise is an important occupational health risk affecting workers' health and putting the workers' health at a high risk. Hence, it is urgent to reduce noise exposure among workers in workplaces by performing regularly industrial noise monitoring and health risk evaluation, strengthening the implementation of safety standards of industrial noise, and raising workers' awareness of wearing earplugs properly, and carrying out high-risk population screening.

\section{Declarations}

\section{Acknowledgments}

The authors thank every worker for their participations in this study.

\section{Authors' contributions}

Conceptualization, YP; investigation, LM; methodology, LM, JZ; data collection, LM; formal analysis, LM; supervision, JZ and LY; writing-original draft, LM; writing-review and editing, JZ, LY and YP; The authors read and approved the final manuscript.

\section{Funding}

This study was supported by the Open Research Fund of State Key Laboratory of Bioelectronics, Southeast University.

\section{Data availability}


The datasets used and analyzed during the current study are available from the corresponding author on reasonable request.

\section{Ethics approval and consent to participate}

The present study was approved by the Ethics Committee of Zhongda Hospital, Affiliated Hospital of Southeast University (approval No: 2020ZDSYLL150-P01). Informed consent was also obtained from all individual participants included in the study.

\section{Consent to publish}

The participant has consented to the submission of the case report to the journal.

\section{Competing interests}

The authors declare that they have no conflicts of interest.

\section{Author details}

${ }^{1}$ Key Laboratory of Environmental Medicine Engineering, Ministry of Education, School of Public Health, Southeast University, Nanjing 210009, China.

\section{References}

1. Licitra G, Fredianelli L, Petri D, Vigotti MA. Annoyance evaluation due to overall railway noise and vibration in Pisa urban areas. Sci Total Environ. 2016; 5681315-1325.

2. Halperin D. Environmental noise and sleep disturbances: A threat to health? Sleep Sci. 2014; 7(4):209-212.

3. Erickson LC, Newman RS. Influences of background noise on infants and children. Curr Dir Psychol Sci. $2017 ; 26(5): 451-457$.

4. Zacarias FF, Molina RH, Ancela JLC, Lopez SL, Ojembarrena AA. Noise Exposure in Preterm Infants Treated with Respiratory Support Using Neonatal Helmets. Acta Acustica United with Acustica. 2013; 99(4):590-597.

5. Miao L, Ji J, Wan L, Zhang J, Yin L, Pu Y. An overview of research trends and genetic polymorphisms for noise-induced hearing loss from 2009 to 2018. Environ Sci Pollut Res Int. 2019; 26(34):34754-34774.

6. Basner M, Babisch W, Davis A, Brink M, Clark C, Janssen S, et al. Auditory and non-auditory effects of noise on health. Lancet. 2014; 383(9925):1325-1332.

7. Nelson DI, Nelson RY, Concha-Barrientos M, Fingerhut M. The global burden of occupational noise-induced hearing loss. Am J Ind Med. 2005; 48(6):446-458.

8. Lie A, Skogstad M, Johannessen HA, Tynes T, Mehlum IS, Nordby KC, et al. Occupational noise exposure and hearing: a systematic review. Int Arch Occup Environ Health. 2016; 89(3):351-372.

9. Tak S, Davis RR, Calvert GM. Exposure to hazardous workplace noise and use of hearing protection devices among US workers-NHANES, 1999-2004. Am J Ind Med. 2009; 52(5):358-371.

10. Seidler AL, Hegewald J, Schubert M, Weihofen VM, Wagner M, Droge P, et al. The effect of aircraft, road, and railway traffic noise on stroke - results of a case-control study based on secondary data. Noise Health. 2018; 20(95):152-161. 
11. Yu SF. [Strengthen the research for the prevention and control of occupational noise-induced hearing loss in our country]. Zhonghua Lao Dong Wei Sheng Zhi Ye Bing Za Zhi. 2016; 34(12):881-883.

12. Zhou J, Shi Z, Zhou L, Hu Y, Zhang M. Occupational noise-induced hearing loss in China: a systematic review and meta-analysis. BMJ Open. 2020; 10(9):e039576.

13. Samelli AG, Santos IS, Padilha F, Gomes RF, Moreira RR, Rabelo CM, et al. Hearing loss, tinnitus, and hypertension: analysis of the baseline data from the Brazilian Longitudinal Study of Adult Health (ELSABrasil). Clinics (Sao Paulo). 2021; 76e2370.

14. Ising $H$, Kruppa B. Health effects caused by noise: evidence in the literature from the past 25 years. Noise Health. 2004; 6(22):5-13.

15. Sbihi H, Davies HW, Demers PA. Hypertension in noise-exposed sawmill workers: a cohort study. Occup Environ Med. 2008; 65(9):643-646.

16. Chang TY, Jain RM, Wang CS, Chan CC. Effects of occupational noise exposure on blood pressure. J Occup Environ Med. 2003; 45(12):1289-1296.

17. Green MS, Schwartz K, Harari G, Najenson T. Industrial noise exposure and ambulatory blood pressure and heart rate. J Occup Med. 1991; 33(8):879-883.

18. Zhao YM, Zhang SZ, Selvin S, Spear RC. A dose response relation for noise induced hypertension. Br J Ind Med. 1991; 48(3):179-184.

19. Tomei G, Fioravanti M, Cerratti D, Sancini A, Tomao E, Rosati MV, et al. Occupational exposure to noise and the cardiovascular system: a meta-analysis. Sci Total Environ. 2010; 408(4):681-689.

20. Lim SS, Vos T, Flaxman AD, Danaei G, Shibuya K, Adair-Rohani H, et al. A comparative risk assessment of burden of disease and injury attributable to 67 risk factors and risk factor clusters in 21 regions, 1990-2010: a systematic analysis for the Global Burden of Disease Study 2010. Lancet. 2012; 380(9859):2224-2260.

21. Skogstad M, Johannessen HA, Tynes T, Mehlum IS, Nordby KC, Lie A. Systematic review of the cardiovascular effects of occupational noise. Occup Med (Lond). 2016; 66(1):10-16.

22. Chen S, Ni Y, Zhang L, Kong L, Lu L, Yang Z, et al. Noise exposure in occupational setting associated with elevated blood pressure in China. BMC Public Health. 2017; 17(1):107.

23. Chang TY, Hwang BF, Liu CS, Chen RY, Wang VS, Bao BY, et al. Occupational noise exposure and incident hypertension in men: a prospective cohort study. Am J Epidemiol. 2013; 177(8):818-825.

24. de Souza TC, Perisse AR, Moura M. Noise exposure and hypertension: investigation of a silent relationship. BMC Public Health. 2015; 15328.

25. Miao L, Wang B, Zhang J, Yin L, Pu Y. A functional SNP in miR-625-5p binding site of AKT2 3'UTR is associated with noise-induced hearing loss susceptibility in the Chinese population. Environ Sci Pollut Res Int. 2021.

26. Clark JG. Uses and abuses of hearing loss classification. ASHA. 1981; 23(7):493-500.

27. Muzet A. Environmental noise, sleep and health. Sleep Med Rev. 2007; 11(2):135-142.

28. Minichilli F, Gorini F, Ascari E, Bianchi F, Coi A, Fredianelli L, et al. Annoyance Judgment and Measurements of Environmental Noise: A Focus on Italian Secondary Schools. Int J Environ Res Public Health. 2018; 15(2).

29. Dratva J, Phuleria HC, Foraster M, Gaspoz JM, Keidel D, Künzli N, et al. Transportation noise and blood pressure in a population-based sample of adults. Environ Health Perspect. 2012; 120(1):50-55. 
30. Masterson EA, Bushnell PT, Themann CL, Morata TC. Hearing Impairment Among Noise-Exposed Workers United States, 2003-2012. MMWR Morb Mortal Wkly Rep. 2016; 65(15):389-394.

31. Maccà I, Scapellato ML, Carrieri M, Maso S, Trevisan A, Bartolucci GB. High-frequency hearing thresholds: effects of age, occupational ultrasound and noise exposure. Int Arch Occup Environ Health. 2015; 88(2):197211.

32. Alabdulwahhab BM, Alduraiby RI, Ahmed MA, Albatli LI, Alhumain MS, Softah NA, et al. Hearing loss and its association with occupational noise exposure among Saudi dentists: a cross-sectional study. BDJ Open. 2016; 216006.

33. Shuster BZ, Depireux DA, Mong JA, Hertzano R. Sex differences in hearing: Probing the role of estrogen signaling. J Acoust Soc Am. 2019; 145(6):3656.

34. Yuan H, Wang X, Hill K, Chen J, Lemasters J, Yang SM, et al. Autophagy attenuates noise-induced hearing loss by reducing oxidative stress. Antioxid Redox Signal. 2015; 22(15):1308-1324.

35. Hormozi M, Ansari-Moghaddam A, Mirzaei R, Dehghan Haghighi J, Eftekharian F. The risk of hearing loss associated with occupational exposure to organic solvents mixture with and without concurrent noise exposure: A systematic review and meta-analysis. Int J Occup Med Environ Health. 2017; 30(4):521-535.

36. Grobler LM, Swanepoel W, Strauss S, Becker P, Eloff Z. Occupational noise and age: A longitudinal study of hearing sensitivity as a function of noise exposure and age in South African gold mine workers. S Afr J Commun Disord. 2020; 67(2):e1-e7.

37. Ahmed HO, Dennis JH, Badran O, Ismail M, Ballal SG, Ashoor A, et al. Occupational noise exposure and hearing loss of workers in two plants in eastern Saudi Arabia. Ann Occup Hyg. 2001; 45(5):371-380.

38. Osibogun A, Igweze IA, Adeniran LO. Noise-induced hearing loss among textile workers in Lagos metropolis. Niger Postgrad Med J. 2000; 7(3):104-111.

39. Shakhatreh FM, Abdul-Baqi KJ, Turk MM. Hearing loss in a textile factory. Saudi Med J. 2000; 21(1):58-60.

40. Li X, Dong Q, Wang B, Song H, Wang S, Zhu B. The Influence of Occupational Noise Exposure on Cardiovascular and Hearing Conditions among Industrial Workers. Sci Rep. 2019; 9(1):11524.

41. Hu H, Sasaki N, Ogasawara T, Nagahama S, Akter S, Kuwahara K, et al. Smoking, Smoking Cessation, and the Risk of Hearing Loss: Japan Epidemiology Collaboration on Occupational Health Study. Nicotine Tob Res. 2019; 21(4):481-488.

42. Tao L, Davis R, Heyer N, Yang Q, Qiu W, Zhu L, et al. Effect of cigarette smoking on noise-induced hearing loss in workers exposed to occupational noise in China. Noise Health. 2013; 15(62):67-72.

43. Wang D, Wang Z, Zhou M, Li W, He M, Zhang X, et al. The combined effect of cigarette smoking and occupational noise exposure on hearing loss: evidence from the Dongfeng-Tongji Cohort Study. Sci Rep. 2017; 7(1):11142.

44. Palmer KT, Griffin MJ, Syddall HE, Coggon D. Cigarette smoking, occupational exposure to noise, and self reported hearing difficulties. Occup Environ Med. 2004; 61(4):340-344.

45. Fransen E, Topsakal V, Hendrickx JJ, Van Laer L, Huyghe JR, Van Eyken E, et al. Occupational noise, smoking, and a high body mass index are risk factors for age-related hearing impairment and moderate alcohol consumption is protective: a European population-based multicenter study. J Assoc Res Otolaryngol. 2008; 9(3):264-276; discussion 261-263. 
46. Rosenhall U, Sixt E, Sundh V, Svanborg A. Correlations between presbyacusis and extrinsic noxious factors. Audiology. 1993; 32(4):234-243.

47. Itoh A, Nakashima T, Arao H, Wakai K, Tamakoshi A, Kawamura T, et al. Smoking and drinking habits as risk factors for hearing loss in the elderly: epidemiological study of subjects undergoing routine health checks in Aichi, Japan. Public Health. 2001; 115(3):192-196.

48. Dzhambov AM, Dimitrova DD. Residential road traffic noise as a risk factor for hypertension in adults: Systematic review and meta-analysis of analytic studies published in the period 2011-2017. Environ Pollut. 2018; 240306-318.

49. Liu J, Xu M, Ding L, Zhang H, Pan L, Liu Q, et al. Prevalence of hypertension and noise-induced hearing loss in Chinese coal miners. J Thorac Dis. 2016; 8(3):422-429.

50. Evrard AS, Lefèvre M, Champelovier P, Lambert J, Laumon B. Does aircraft noise exposure increase the risk of hypertension in the population living near airports in France? Occup Environ Med. 2017; 74(2):123-129.

51. Talukder MA, Johnson WM, Varadharaj S, Lian J, Kearns PN, El-Mahdy MA, et al. Chronic cigarette smoking causes hypertension, increased oxidative stress, impaired NO bioavailability, endothelial dysfunction, and cardiac remodeling in mice. Am J Physiol Heart Circ Physiol. 2011; 300(1):H388-396.

52. Kuang D, Yu YY, Tu C. Bilateral high-frequency hearing loss is associated with elevated blood pressure and increased hypertension risk in occupational noise exposed workers. PLoS One. 2019; 14(9):e0222135.

53. Iversen B, Jacobsen BK, Lochen ML. Active and passive smoking and the risk of myocardial infarction in 24,968 men and women during 11 year of follow-up: the Tromso Study. Eur J Epidemiol. 2013; 28(8):659667.

54. He Y, Lam TH, Jiang B, Wang J, Sai X, Fan L, et al. Passive smoking and risk of peripheral arterial disease and ischemic stroke in Chinese women who never smoked. Circulation. 2008; 118(15):1535-1540.

55. Virdis A, Giannarelli C, Neves MF, Taddei S, Ghiadoni L. Cigarette smoking and hypertension. Curr Pharm Des. 2010; 16(23):2518-2525.

56. van Kempen EE, Kruize H, Boshuizen HC, Ameling CB, Staatsen BA, de Hollander AE. The association between noise exposure and blood pressure and ischemic heart disease: a meta-analysis. Environ Health Perspect. 2002; 110(3):307-317.

57. Ghotbi MR, Khanjani N, Barkhordari A, Rahimi Moghadam S, Mozaffari A, Gozashti MH. Changes in urinary catecholamines in response to noise exposure in workers at Sarcheshmeh Copper Complex, Kerman, Iran. Environ Monit Assess. 2013; 185(11):8809-8814.

58. Münzel T, Gori T, Babisch W, Basner M. Cardiovascular effects of environmental noise exposure. Eur Heart J. $2014 ; 35(13): 829-836$.

59. Gan WQ, Mannino DM. Occupational Noise Exposure, Bilateral High-Frequency Hearing Loss, and Blood Pressure. J Occup Environ Med. 2018; 60(5):462-468.

60. Stokholm ZA, Bonde JP, Christensen KL, Hansen AM, Kolstad HA. Occupational noise exposure and the risk of hypertension. Epidemiology. 2013; 24(1):135-142.

61. Zamanian Z, Rostami R, Hasanzadeh J, Hashemi H. Investigation of the effect of occupational noise exposure on blood pressure and heart rate of steel industry workers. J Environ Public Health. 2013; 2013256060. 
62. Ni CH, Chen ZY, Zhou Y, Zhou JW, Pan JJ, Liu N, et al. Associations of blood pressure and arterial compliance with occupational noise exposure in female workers of textile mill. Chin Med J (Engl). 2007; 120(15):1309-1313.

63. Tarter SK, Robins TG. Chronic noise exposure, high-frequency hearing loss, and hypertension among automotive assembly workers. J Occup Med. 1990; 32(8):685-689.

64. Chang TY, Liu CS, Huang KH, Chen RY, Lai JS, Bao BY. High-frequency hearing loss, occupational noise exposure and hypertension: a cross-sectional study in male workers. Environ Health. 2011; 1035.

\section{Tables}


Table 1 Demographic characteristics of the study occupational noise exposure workers

\begin{tabular}{|c|c|c|c|}
\hline Characteristics & Mean \pm SD & $\mathrm{n}$ & $\%$ \\
\hline \multicolumn{4}{|l|}{ Gender } \\
\hline Female & & 10750 & 25.24 \\
\hline Male & & 31838 & 74.76 \\
\hline Age (years) & $36.58 \pm 9.56$ & & \\
\hline $18-34$ & & 18865 & 44.30 \\
\hline $35-44$ & & 13363 & 31.38 \\
\hline$\geq 45$ & & 10360 & 24.33 \\
\hline Noise exposure time (years) & $9.20 \pm 8.38$ & & \\
\hline$<5$ & & 16425 & 38.57 \\
\hline $5-10$ & & 12790 & 30.03 \\
\hline$>10$ & & 13373 & 31.40 \\
\hline Noise exposure level (dB (A)) & $88.07 \pm 7.39$ & & \\
\hline$\leq 85$ & & 16009 & 37.59 \\
\hline $86-91$ & & 8484 & 19.92 \\
\hline$\geq 92$ & & 18095 & 42.49 \\
\hline \multicolumn{4}{|l|}{ Smoking status } \\
\hline No & & 28346 & 66.56 \\
\hline Yes & & 14242 & 33.44 \\
\hline \multicolumn{4}{|l|}{ Drinking status } \\
\hline No & & 28311 & 66.48 \\
\hline Yes & & 14277 & 33.52 \\
\hline
\end{tabular}

Binaural high frequency threshold on average (dB) $\quad 23.09 \pm 11.32$

$S D$, standard deviation; $d B$, decibel 
Table 2 Prevalence of NIHL of different severity in the study occupational noise exposure workers

\begin{tabular}{lllll}
\hline Variable & BHFTA $(\mathrm{dB})$ & $\mathrm{n}$ & Prevalence (\%) & Proportion (\%) \\
\hline Normal hearing & $\leq 25$ & 32205 & - & - \\
\hline Mild & $26-40$ & 7139 & 16.76 & 68.76 \\
\hline Moderate & $41-70$ & 3025 & 7.1 & 29.13 \\
\hline Severe & $71-90$ & 191 & 0.45 & 1.84 \\
\hline Profound & $\geq 91$ & 28 & 0.07 & 0.27 \\
\hline Total & - & 42588 & 24.38 & 100.00 \\
\hline
\end{tabular}

$N I H L$, noise-induced hearing loss; $B H F T A$, binaural high frequency threshold on average; $d B$, decibel

Table 3 Blood pressure level and prevalence of hypertension in the study occupational noise exposure workers

\begin{tabular}{llll} 
Variable & Mean \pm SD & $\mathrm{n}$ & $\%$ \\
\hline Systolic blood pressure $(\mathrm{mmHg})$ & $126.85 \pm 15.94$ & & \\
\hline Diastolic blood pressure $(\mathrm{mmHg})$ & $79.94 \pm 11.61$ & & 74.60 \\
\hline Normotension & & 31772 & 25.40
\end{tabular}

$S D$, standard deviation 
Table 4 Stratified analysis of BHFTA and prevalence of NIHL by different variable groups

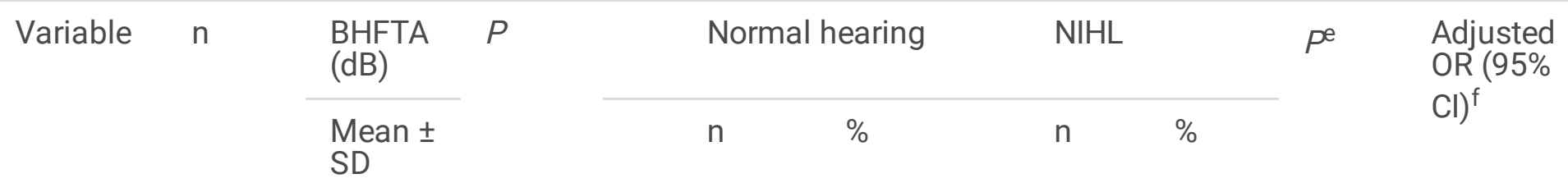

\section{Gender}

\begin{tabular}{|c|c|c|c|c|c|c|c|c|c|}
\hline Female & 10750 & $\begin{array}{l}22.14 \pm \\
9.60\end{array}$ & $\begin{array}{l}< \\
0.001^{a}\end{array}$ & 8529 & 79.34 & 2221 & 20.66 & $\begin{array}{l}< \\
0.001\end{array}$ & $\begin{array}{l}1.00 \\
\text { (ref) }\end{array}$ \\
\hline Male & 31838 & $\begin{array}{l}23.41 \pm \\
11.83\end{array}$ & & 23676 & 74.36 & 8162 & 25.64 & & $\begin{array}{l}1.51 \\
(1.41- \\
1.61)\end{array}$ \\
\hline
\end{tabular}

Age

(years)

$\begin{array}{lllllllll}<35 & 18865 & \begin{array}{l}20.69 \pm \\ 8.06\end{array} & \begin{array}{l}< \\ 0.001^{\mathrm{b}}\end{array} & 16271 & 86.25 & 2594 & 13.75 & \begin{array}{l}1.00 \\ 0.001\end{array} \\ \text { (ref) }\end{array}$

Noise

exposure

time

(years)

\begin{tabular}{|c|c|c|c|c|c|c|c|c|c|}
\hline$<5$ & 16425 & $\begin{array}{l}20.46 \pm \\
7.67\end{array}$ & $\begin{array}{l}< \\
0.001^{b}\end{array}$ & 14673 & 89.33 & 1752 & 10.67 & < 0.001 & $\begin{array}{l}1.00 \\
\text { (ref) }\end{array}$ \\
\hline $5-10$ & 12790 & $\begin{array}{l}24.30 \pm \\
12.06^{c}\end{array}$ & & 8859 & 69.27 & 3931 & 30.73 & & $\begin{array}{l}3.33 \\
(3.12 \\
3.54)\end{array}$ \\
\hline$>10$ & 13373 & $\begin{array}{l}25.16 \pm \\
13.51^{\mathrm{cd}}\end{array}$ & & 8673 & 64.85 & 4700 & 35.15 & & $\begin{array}{l}2.73 \\
(2.55 \\
2.92)\end{array}$ \\
\hline
\end{tabular}

Noise

exposure

level (dB

(A))

\begin{tabular}{|c|c|c|c|c|c|c|c|c|c|}
\hline$\leq 85$ & 16009 & $\begin{array}{l}80.23 \pm \\
4.79\end{array}$ & $\begin{array}{l}< \\
0.001^{b}\end{array}$ & 12637 & 78.94 & 3372 & 21.06 & 0.001 & $\begin{array}{l}1.00 \\
\text { (ref) }\end{array}$ \\
\hline $86-91$ & 8484 & $\begin{array}{l}88.15 \pm \\
1.91^{c}\end{array}$ & & 6231 & 73.44 & 2253 & 26.56 & & $\begin{array}{l}1.36 \\
(1.27- \\
1.45)\end{array}$ \\
\hline$\geq 92$ & 18095 & $\begin{array}{l}94.97 \pm \\
2.17^{\mathrm{cd}}\end{array}$ & & 13337 & 73.71 & 4758 & 26.29 & & $\begin{array}{l}1.30 \\
(1.23-\end{array}$ \\
\hline
\end{tabular}




\begin{tabular}{|c|c|c|c|c|c|c|c|c|c|}
\hline \multicolumn{10}{|c|}{$\begin{array}{l}\text { Smoking } \\
\text { status }\end{array}$} \\
\hline No & 28346 & $\begin{array}{l}22.44 \pm \\
10.57\end{array}$ & $\begin{array}{l}< \\
0.001^{a}\end{array}$ & 22252 & 78.50 & 6094 & 21.50 & $\begin{array}{l}< \\
0.001\end{array}$ & $\begin{array}{l}1.00 \\
\text { (ref) }\end{array}$ \\
\hline Yes & 14242 & $\begin{array}{l}24.38 \pm \\
12.58\end{array}$ & & 9953 & 69.88 & 4289 & 30.12 & & $\begin{array}{l}1.10 \\
(1.04- \\
1.16)\end{array}$ \\
\hline \multicolumn{10}{|c|}{$\begin{array}{l}\text { Drinking } \\
\text { status }\end{array}$} \\
\hline No & 28311 & $\begin{array}{l}22.88 \pm \\
11.03\end{array}$ & $\begin{array}{l}< \\
0.001^{a}\end{array}$ & 21643 & 76.45 & 6668 & 23.55 & $<.001$ & $\begin{array}{l}1.00 \\
\text { (ref) }\end{array}$ \\
\hline Yes & 14277 & $\begin{array}{l}23.51 \pm \\
11.86\end{array}$ & & 10562 & 73.98 & 3715 & 26.02 & & $\begin{array}{l}0.95 \\
(0.90- \\
1.00)\end{array}$ \\
\hline
\end{tabular}

$B H F T A$, binaural high frequency threshold on average (dB); $N I H L$, noise-induced hearing loss; $d B$, decibel; $S D$, standard deviation; $O R$, odds ratio; $C l$, confidence interval

a $t$-test of the difference between two groups

${ }^{b}$ Kruskal-Wallis test of the difference between three groups

${ }^{c}$ Mann-Whitney test for a significant difference compared with the age $<35$ years, noise exposure time $<5$ years and noise exposure level $\leq 85 \mathrm{~dB}(\mathrm{~A})$ groups

d Mann-Whitney test for a significant difference compared with the age 35-44 years, noise exposure time 5-10 years and noise exposure level 86-91 dB (A) groups

e Two-sided $\chi^{2}$ test for the frequency distributions of variables between groups

${ }^{\mathrm{f}}$ Adjusted for gender, age, noise exposure time, noise exposure level, smoking and drinking status in logistic regression model 
Table 5 Stratified analysis of the levels of SBP and DBP and prevalence of hypertension by different variable groups

\begin{tabular}{|c|c|c|c|c|c|c|c|c|c|}
\hline \multirow[t]{2}{*}{ Variable } & \multirow[t]{2}{*}{$\mathrm{n}$} & $\begin{array}{l}\text { Resting } \\
\text { SBP }\end{array}$ & \multirow[t]{2}{*}{$P$} & $\begin{array}{l}\text { Resting } \\
\text { DBP }\end{array}$ & \multirow[t]{2}{*}{$P$} & \multicolumn{2}{|c|}{ Hypertension } & \multirow[t]{2}{*}{$p^{e}$} & \multirow{2}{*}{$\begin{array}{l}\text { Adjusted } \\
\text { OR (95\% } \\
\mathrm{Cl})^{f}\end{array}$} \\
\hline & & $\begin{array}{l}\text { Mean } \pm \\
\text { SD }(\mathrm{mm} \\
\mathrm{Hg})\end{array}$ & & $\begin{array}{l}\text { Mean } \pm \\
\text { SD }(m m \\
H g)\end{array}$ & & $\mathrm{n}$ & $\%$ & & \\
\hline
\end{tabular}

Gender

\begin{tabular}{|c|c|c|c|c|c|c|c|c|c|}
\hline Female & 10750 & $\begin{array}{l}122.53 \pm \\
15.91\end{array}$ & $\begin{array}{l}< \\
0.001^{a}\end{array}$ & $\begin{array}{l}76.64 \pm \\
10.90\end{array}$ & $\begin{array}{l}< \\
0.001^{a}\end{array}$ & 1808 & 16.82 & $<.001$ & $\begin{array}{l}1.00 \\
\text { (ref) }\end{array}$ \\
\hline Male & 31838 & $\begin{array}{l}128.31 \pm \\
15.68\end{array}$ & & $\begin{array}{l}81.06 \pm \\
11.64\end{array}$ & & 9008 & 28.29 & & $\begin{array}{l}2.18 \\
(2.04- \\
2.34)\end{array}$ \\
\hline
\end{tabular}

Age (years)

\begin{tabular}{|c|c|c|c|c|c|c|c|c|c|}
\hline$<35$ & 18865 & $\begin{array}{l}123.28 \pm \\
13.88\end{array}$ & $\begin{array}{l}< \\
0.001^{b}\end{array}$ & $\begin{array}{l}76.85 \pm \\
10.37\end{array}$ & $\begin{array}{l}< \\
0.001^{b}\end{array}$ & 2832 & 15.01 & & $\begin{array}{l}1.00 \\
\text { (ref) }\end{array}$ \\
\hline $35-44$ & 13363 & $\begin{array}{l}127.32 \pm \\
16.01^{c}\end{array}$ & & $\begin{array}{l}80.86 \pm \\
11.83^{c}\end{array}$ & & 3739 & 27.98 & $\begin{array}{l}< \\
0.001\end{array}$ & $\begin{array}{l}2.32 \\
(2.18- \\
2.47)\end{array}$ \\
\hline$>44$ & 10360 & $\begin{array}{l}132.74 \pm \\
17.45^{\mathrm{cd}}\end{array}$ & & $\begin{array}{l}84.38 \pm \\
11.83^{\mathrm{cd}}\end{array}$ & & 4245 & 40.97 & $\begin{array}{l}< \\
0.001\end{array}$ & $\begin{array}{l}3.82 \\
(3.58- \\
4.07)\end{array}$ \\
\hline
\end{tabular}

Noise

exposure

time (years)

\begin{tabular}{|c|c|c|c|c|c|c|c|c|c|}
\hline$<5$ & 16425 & $\begin{array}{l}124.52 \pm \\
14.89\end{array}$ & $\begin{array}{l}< \\
0.001^{b}\end{array}$ & $\begin{array}{l}77.98 \pm \\
10.92\end{array}$ & $\begin{array}{l}< \\
0.001^{b}\end{array}$ & 3124 & 19.02 & & $\begin{array}{l}1.00 \\
\text { (ref) }\end{array}$ \\
\hline $5-10$ & 12790 & $\begin{array}{l}126.70 \pm \\
15.95^{c}\end{array}$ & & $\begin{array}{l}79.63 \pm \\
11.65^{c}\end{array}$ & & 3077 & 24.06 & $\begin{array}{l}< \\
0.001\end{array}$ & $\begin{array}{l}1.14 \\
(1.07- \\
1.21)\end{array}$ \\
\hline$>10$ & 13373 & $\begin{array}{l}129.85 \pm \\
16.66^{c d}\end{array}$ & & $\begin{array}{l}82.67 \pm \\
11.88^{c d}\end{array}$ & & 4615 & 34.51 & $\begin{array}{l}< \\
0.001\end{array}$ & $\begin{array}{l}1.20 \\
(1.13- \\
1.28)\end{array}$ \\
\hline
\end{tabular}

Noise

exposure

level (dB (A))

\begin{tabular}{|c|c|c|c|c|c|c|c|c|c|}
\hline$\leq 85$ & 16009 & $\begin{array}{l}126.26 \pm \\
15.64\end{array}$ & $\begin{array}{l}<.001^{b} \\
\end{array}$ & $\begin{array}{l}79.53 \pm \\
11.34\end{array}$ & $\begin{array}{l}< \\
0.001^{b}\end{array}$ & 3748 & 23.41 & $\begin{array}{l}< \\
0.001\end{array}$ & $\begin{array}{l}1.00 \\
\text { (ref) }\end{array}$ \\
\hline $86-91$ & 8484 & $\begin{array}{l}127.56 \pm \\
16.23^{c}\end{array}$ & & $\begin{array}{l}80.44 \pm \\
11.96^{c}\end{array}$ & & 2314 & 27.28 & & $\begin{array}{l}1.22 \\
(1.15- \\
1.30)\end{array}$ \\
\hline$\geq 92$ & 18095 & $\begin{array}{l}127.04 \pm \\
16.04^{\mathrm{cd}}\end{array}$ & & $\begin{array}{l}80.08 \pm \\
11.68^{\text {cd }}\end{array}$ & & 4754 & 26.27 & & $\begin{array}{l}1.15 \\
(1.09- \\
1.21)\end{array}$ \\
\hline
\end{tabular}


Smoking

status

\begin{tabular}{|c|c|c|c|c|c|c|c|c|c|}
\hline No & 28346 & $\begin{array}{l}125.45 \pm \\
15.76\end{array}$ & $\begin{array}{l}< \\
0.001^{a}\end{array}$ & $\begin{array}{l}78.70 \pm \\
11.40\end{array}$ & $\begin{array}{l}< \\
0.001^{a}\end{array}$ & 6154 & 21.71 & & $\begin{array}{l}1.00 \\
\text { (ref) }\end{array}$ \\
\hline Yes & 14242 & $\begin{array}{l}129.63 \pm \\
15.92\end{array}$ & & $\begin{array}{l}82.42 \pm \\
11.64\end{array}$ & & 4662 & 32.73 & $\begin{array}{l}< \\
0.001\end{array}$ & $\begin{array}{l}1.11 \\
(1.05- \\
1.17)\end{array}$ \\
\hline
\end{tabular}

Drinking

status

\begin{tabular}{|c|c|c|c|c|c|c|c|c|c|}
\hline No & 28311 & $\begin{array}{l}126.02 \pm \\
15.96\end{array}$ & $\begin{array}{l}< \\
0.001^{a}\end{array}$ & $\begin{array}{l}79.27 \pm \\
11.54\end{array}$ & $\begin{array}{l}< \\
0.001^{a}\end{array}$ & 6675 & 23.58 & & $\begin{array}{l}1.00 \\
\text { (ref) }\end{array}$ \\
\hline Yes & 14277 & $\begin{array}{l}128.50 \pm \\
15.77\end{array}$ & & $\begin{array}{l}81.27 \pm \\
11.65\end{array}$ & & 4141 & 29.00 & $\begin{array}{l}< \\
0.001\end{array}$ & $\begin{array}{l}1.01 \\
(0.96- \\
1.06)\end{array}$ \\
\hline
\end{tabular}

$S B P$, systolic blood pressure; $D B P$, diastolic blood pressure; $S D$, standard deviation; $O R$, odds ratio; $C l$, confidence interval

a $t$-test of the difference between two groups

${ }^{b}$ Kruskal-Wallis test of the difference between three groups

${ }^{c}$ Mann-Whitney test for a significant difference compared with the age $<35$ years, noise exposure time $<5$ years and noise exposure level $\leq 85 \mathrm{~dB}(\mathrm{~A})$ groups

${ }^{d}$ Mann-Whitney test for a significant difference compared with the age 35-44 years, noise exposure time 5-10 years and noise exposure level 86-91 dB (A) groups

e Two-sided $\chi^{2}$ test for the frequency distributions of variables between groups

${ }^{f}$ Adjusted for gender, age, noise exposure time, noise exposure level, smoking and drinking status in logistic regression model 
Table 6 The association between NIHL and hypertension

\begin{tabular}{|c|c|c|c|c|c|c|}
\hline \multirow[t]{2}{*}{ Group } & \multirow[t]{2}{*}{$\mathrm{n}$} & \multirow{2}{*}{$\begin{array}{l}\text { Resting SBP } \\
\text { Mean } \pm \text { SD (mm } \\
\text { Hg) }\end{array}$} & \multirow{2}{*}{$\begin{array}{l}\text { Resting DBP } \\
\text { Mean } \pm \text { SD (mm } \\
\mathrm{Hg})\end{array}$} & \multicolumn{2}{|c|}{ Hypertension } & \multirow{2}{*}{$\begin{array}{l}\text { Adjusted OR } \\
(95 \% \mathrm{Cl}) \mathrm{c}\end{array}$} \\
\hline & & & & $\mathrm{n}$ & $\%$ & \\
\hline $\begin{array}{l}\text { Normal } \\
\text { hearing }\end{array}$ & 32205 & $125.82 \pm 15.48$ & $79.23 \pm 11.32$ & 7468 & 23.19 & 1.00 (ref) \\
\hline $\mathrm{NIHL}$ & 10383 & $130.03 \pm 16.89$ & $82.16 \pm 12.21$ & 3348 & 32.25 & $\begin{array}{l}1.07(1.02- \\
1.13)\end{array}$ \\
\hline$P$ & & $<0.001 a$ & $<0.001 a$ & \multicolumn{2}{|c|}{$<0.001 b$} & \\
\hline
\end{tabular}

$S B P$, systolic blood pressure; $D B P$, diastolic blood pressure; $S D$, standard deviation; $O R$, odds ratio; $C l$, confidence interval

a t-test of the difference between two groups

b Two-sided $\chi^{2}$ test for the frequency distributions of variables between two groups

${ }^{c}$ Adjusted for gender, age, noise exposure time, noise exposure level, smoking and drinking status in logistic regression model 